\title{
Pengedukasian Kesehatan Reproduksi dan Pencegahan Kejahatan Seksual Online dalam Upaya Sekolah Membentuk Karakter Remaja Bertanggungjawab
}

\author{
Deni Nasir Ahmad \\ Fakultas MIPA, Universitas Indraprasta PGRI \\ deninasirahmad@gmail.com
}

\begin{abstract}
The purpose of this extension activity is so that students gain knowledge about their reproductive health and how to use social media online wisely. This activity is carried out so that students in this case the age of adolescents approaching adults gain knowledge and the foundation of the character of responsibility to themselves so that teenagers can fortify themselves through knowledge that has been given thoroughly and build self-confidence through character building material for students. In carrying out the community service activities, the servant performs an approach or method of dedication in the form of counseling with material exposure activities, giving questionnaires and interactive discussions between devotees and students. From the results of community service activities that have been carried out, it can be concluded that the service participants obtain new knowledge about reproductive health and efforts to prevent sexual violence on social media online and for servants to gain new knowledge and experience on how to approach character education after adolescence in the age of globalization.
\end{abstract}

Keywords: Reproductive Health; Sexual Crime; Adolescence

\begin{abstract}
Abstrak
Tujuan dari kegiatan penyuluhan ini adalah agar para peserta didik memperoleh pengetahuan mengenai kesehatan reproduksi mereka dan cara penggunaan media sosial secara online dengan bijak. Kegiatan ini dilakukan agar peserta didik dalam hal ini usia remaja mendekati dewasa memperoleh pengetahuan dan landasan karakter tanggung jawab pada dirinya sendiri agar remaja dapat membentengi dirinya melalui pengetahuan yang telah diberikan secara tuntas dan membangun kepercayaan diri melalui materi pembangunan karakter pada peserta didik. Dalam melakukan kegiatan pengabdian masyarakat pengabdi melakukan pendekatan atau metode pengabdian yakni berupa penyuluhan dengan kegiatan pemaparan materi, pemberian angket dan diskusi interaktif antara pengabdi dengan peserta didik. Dari hasil kegiatan pengabdian masyarakat yang telah dilakukan dapat disimpulkan bahwa para peserta pengabdi memperoleh pengetahuan baru mengenai kesehatan reproduksi dan upaya pencegahan kekerasan seksual di media sosial secara online dan bagi pengabdi memperoleh pengetahuan dan pengalaman baru bagaimana cara melakukan pendekatan pendidikan karakter pada usia remaja pada zaman globalisasi.
\end{abstract}

Kata Kunci : Kesehatan Reproduksi; Kejahatan Seksual; Remaja 


\section{A. PENDAHULUAN}

Tekhnologi terus berkembang setiap hari, setiap bulan dan setiap tahun sehingga banyak inovasi-inosvasi yang bermunculan di segala bidang. Misalkan di bidang kesehatan adanya tangan cyber atau tangan robot dipergunakan bagi pasien yang telah kehilangan tangan sehingga pasien tersebut dapat melakukan aktivitasnya lagi ataupun kecanggihan teknologi komunikasi dimana masyarakat tidak perlu repot lagi berkomunikasi kepada sanak saudara yang jauh tempatnya untuk mengucapkan selamat lebaran atau natalan. Kemudahan tekhnologi disegala bidang memberikan banyak pengaruh bagi masyarakat, yakni dampak positif teknologi yaitu dari masyarakat tradisional menjadi masyarakat modern sedangkan dampak negatif, misalkan tekhnologi membuat masyarakat menjadi malas, komunikasi biasanya dua arah, tatap muka dan berkumpul dengan teman, orang tua dan saudara adanya tekhnologi menyebabkan sudah tidak ada lagi untuk berkumpul dan berkomunikasi hanya sebatas pesan dan video saja.

Berdasarkan penelitian tindak kekerasan seksual pada remaja dilakukan oleh orang terdekat dari korban, misalkan: pacar, teman, atau sahabat. Tindakan kekerasan akibat dari seseorang berpacaran (Dating Violence) secara fisik menurut WHO (World Health Organitation) (2012), seperti: cidera $(55 \%)$, peningkatan resiko bunuh diri $(22 \%)$, kematian $(70 \%)$, dan peningkatan kekerasan yang terjadi selama kehamilan (40\%). Sedangkan kekerasan berdampak emosional dan kesehatan menurut Bonomi seperti merokok $(3,95 \%)$, depresi $(2,00 \%)$, penurunan nafsu makan $(1,98 \%)$, dan penurunan berat badan $(4,33 \%)$ (Oktaviani, 2016). Tindakan kekerasan seksual selain oleh orang terdekat penyebab lainnya bisa dari trauma, penyimpangan seksual dan media sosial berupa situs porno sehingga akhirnya menimbulkan terjadinya pelecehan seksual. Menurut Diah Viska Rahmawati dkk (2002) dari hasil penelitian yakni dari sepuluh sampel uji, sembilan diantaranya orang merasa terangsang gairah seksualnya akibat melihat gambargambar porno di web tersebut dan memiliki keinginan untuk memuaskan dorongan seks yang dirasakan serta satu orang subjek mengaku pernah melampiaskannya dengan melakukan oral sex.

Dari hasil penelitian dan survey tersebut sudah sangat mengkhawatirkan perkembangan remaja saat ini dikarenakan sudah banyaknya penyebab yang akan mengakibatkan pikiran dan perbuatan remaja dari aktivitas berpacaran dan membuka situs porno akan terjadinya penyimpangan dan pelecehan seksual yang dilakukan oleh remaja. Perilaku penyimpangan seksual menurut Gagnon dan Simon membagi perilaku seksual dalam kaitannya dengan masalah sosial ke dalam tiga tipe antara lain tolerated sex variance (kontak anal-oral genital pasangan heteroseksual, masturbasi, dan premarital-extramarital intercourse), asocial sex variance (incest, child molestation, pemerkosaan, exhibitionism, dan voyeurism), dan structured variance (homoseksualitas, prostitusi, dan pornografi (Nuandri, 2014)

Sedangkan pelecehan seksual adalah segala macam bentuk perilaku yang berkonotasi seksual yang dilakukan secara sepihak dan tidak diharapkan oleh orang yang menjadi sasaran hingga menimbulkan reaksi negatif, seperti: rasa malu, marah, tersinggung dan sebagainya pada diri orang yang menjadi korban pelecehan. Menurut Triwijati dan Amira (2011), penyalahgunaan kekuasaan atau otoritas, sekalipun pelaku mencoba meyakinkan korban dan dirinya sendiri bahwa ia melakukannya karena seks atau romantisme Oleh karena itu perlu dilakukan pemberian pelayanan dan penyuluhan mengenai cara pencegahan 
kejahatan seksual online, pelecehan dan penyimpangan seksual pada remaja.

Remaja yang hidup pada zaman tekhnologi canggih dan modern membuat remaja menjadi tidak perduli dengan lingkungannya, pemurung, tidak percaya diri, mudah menyerah, malas dan takut untuk berinteraksi dengan kelompok lainnya. Permasalahan tersebut membuat remaja memperoleh banyak kesulitan mulai dari pembulian di media sosial, tindak kejahatan seksual sampai kepenculikan remaja. Tindak kejahatan seksual yang sering dialami oleh remaja khususnya remaja putri yakni adanya pelecehan yang dilakukan oleh pelaku seperti memegang bagian tubuh, berkata seksual, bahkan sampai pemerkosaan. Tindakan pelecehan yang dilakukan oleh pelaku disebabkan adanya gejala kejiwaan yakni berupa penyimpangan seksual seperti, suka dengan anak kecil (pedofil), suka dengan sejenis dan bahkan ada yang lebih ekstrim suka dengan diri sendiri atau media lainnya, seperti tembok, sabun atau hewan peliharaan. Untuk melancarkan aksi kejahatan seksual pelaku menggunakan media sosial online untuk mencari korban kejahatan seksual yang akan ia lakukan. Tindak kekerasan seksual yang dilakukan oleh pelaku tersebut perlu dicegah agar tidak mewabah dan menjadi tindak kekerasan seksual secara fisik.

Hal tersebut sudah sangat mengkhawatirkan sehingga perlu peran serta seluruh unit pendidikan seperti kedua orang tua mengawasi kegiatan remaja dalam keluarga, pembinaan karakter di sekolah serta masyarakat sebagai unit besar pelindung remaja agar terhindar dari kejahatan seksual melalui media online. Peran serta pemerintah juga sangat diharapkan karena pemerintah sebagai pengawas dan pemberi kebijakan juga harus mengambil tindakan untuk pencegahan terhadap maraknya wabah tindak kejahatan seksual yang dilakukan secara online.
Peran sekolah dalam pencegahan tindak kekerasan seksual melalui pembinaan dan penyuluhan perlu dilakukan dikarenakan remaja harus diberikan pengetahuan dan pemahaman mengenai dampak yang akan terjadi apabila mereka melakukan tindak kekerasan seksual secara online baik melalui pesan pembulian, pesan menghina secara genetik dan lain sebaginya. Pembinaan dan pelayanan dalam pembelajaran dalam kurikulum Sekolah Menengah Atas (SMA) Nurul Hikmah Jonggol, Bogor-Jawa Barat tahun ajaran 2016/2017 alam membangun pendidikan berkarakter baru dilakukan pada saat Masa Orentasi Peserta didik (MOPD) saja berupa pendidikan karakter agama dan profil sekolah.

Dari permasalahan tersebut menjelaskan bahwa ada rasa kekhawatiran sekolah terhadap peserta didik dimana banyaknya peserta didik menggunakan media sosial membuat para pendidik menjadi khawatir akan dampak yang ditimbulkan dari media sosial secara online. Tidak jarang media online menghasilkan tindak kejahatan mulai dari penipuan, tindak pembulian bahkan sampai tindak kekerasan seksual melalui media online tersebut. Permasalahan tersebutlah membuat para pendidik khawatir takut peserta didik yang di didiknya terjerumus kepada tindakan kekerasan seksual sebagai pelaku atau sebagai korban dari tindakan kekerasan seksual yang berasal dari perkenalan di media sosial akhirnya terkena tindakan kekerasan seksual. Permasalahan tersebut dapat dihindari dengan cara diadakan tindakan pencegahan melalui aktifitas di luar sekolah yang positif atau di buat penyuluhan atau pelatihan mengenai tindakan pencegahan kekerasan seksual.

Sekolah Menengah Atas (SMA) Nurul Hikmah Jonggol, Bogor Jawa Barat berisikan peserta didik yang telah memasuki masa peralihan dari remaja ke tingkat dewasa, yang menyebabkan 
perlunya ada pengawasan dari berbagai pihak yakni, orang tua, sekolah dan masyarakat. Pengawasan bisa dilakukan dengan terus berinteraksi dan berkomunikasi dengan remaja tersebut agar tidak terjerumus ke tindakan kekerasan seksual pada remaja. Permasalahan yang sering ditemukan pada Sekolah Menengah Atas (SMA) Nurul Hikmah Jonggol, BogorJawa Barat tahun ajaran 2016/2017 adalah banyaknya peserta didik dalam menggunakan media sosial secara online belum adanya pengawasan dan belum diberikan pemantapan karakter bertanggung jawab pada peserta didik. Oleh sebab itu Sekolah Menengah Atas (SMA) Nurul Hikmah Jonggol, Bogor Jawa Barat selain membuat program pemantapan agama juga memberikan pendidikan karakter melalui penyuluhan dan pelatihan. Dari permasalahan tersebut kami tim pengabdi melakukan kegiatan pengabdian masyarakat guna memantapkan karakter dan mewujudkan program sekolah.

Perlunya dilakukan tindakan pelayanan pencegahan terhadap kekerasan seksual secara online maka kami tim pengabdi yang terdiri dari mahasiswa dan dosen pembimbing memberikan beberapa pelayanan berupa pembinaan dan pelatihan kepada peserta didik yakni:

a. Cara mengantisipasi dan penolakan kepada pelaku pelecehan seksual online agar tidak melakukan tindakan merugikan.

b. Tindakan menangani pelecehan seksual bila menjadi korban tindakan pelecehan dan kekerasan seksual.

c. Memberikan informasi mengenai memelihara kesehatan reproduksi agar terhindar dari penyakit seksual dan mengedukasi para remaja mengenai hubungan antara pria dan wanita dalam hubungan "seksual", seperti: berpacaran, bersahabat dengan lawan jenis.

Target luaran dalam melakukan kegiatan pengabdian masyarakat oleh tim pengabdi lakukan para peserta didik dapat : a. Memahami cara mengantisipasi dan melakukan penolakan kepada pelaku pelecehan seksual online agar tidak melakukan tindakan merugikan.

b. Melakukan tindakan penanganan pelecehan seksual bila menjadi korban tindakan pelecehan dan kekerasan seksual.

c. Mampu memelihara kesehatan reproduksi agar terhindar dari penyakit seksual dan remaja diharapkan dapat menghindari dan menjaga diri pada hubungan yang negatif antara pria dan wanita dalam hubungan "seksual", seperti: berpacaran, bersahabat dengan lawan jenis.

\section{B. PELAKSAAAN DAN METODE}

$\begin{array}{ccr}\text { Dalam } & \text { melakukan } & \text { kegiatan } \\ \text { pengabdian } & \text { masyarakat } & \text { pengabdi } \\ \text { melakukan } & \text { pendekatan atau } & \text { metode }\end{array}$ pengabdian yakni berupa penge-dukasian dan pelatihan pencegahan kejahatan seksual online dan kese-hatan reproduksi remaja dengan tahapan kegiatan pemaparan materi, diskusi interaktif berupa pelatihan dan penanganan pencegahan kejahatan seksual online (baik dari segi sebelum menjadi korban sampai menjadi korban) sebagai timbal balik dari peserta didik maka tim pengabdi memberikan angket/kuesioner ber-kaitan dengan tindak kekerasan seksual secara online antara pengabdi dengan peserta didik. Kegiatan dilakukan selama 180 menit atau 3 jam dihadiri oleh perwakilan Organisasi Siswa Intra Sekolah (OSIS) dan peserta didik kelas XI dan XII. Kegiatan pengabdian ini dibagi atas 3 pemateri dengan masingmasing pemateri memberikan materi penge-dukasian yang berkaitan dengan kesehatan reproduksi remaja dan pencegahaan terhadap kejahatan seksual online. Pemateri pertama memberikan materi mengenai kese-hatan reproduksi. 
Pemateri kedua mengenai pengedukasian pemanfaatan media online sebagai sarana positif dan keamanan media online. Pemateri ketiga mengedukasi seksual remaja dari segi agama dan penanaman karakter pada remaja. Setelah pemaparan materi tim pengabdi melakukan diskusi berupa tanya jawab secara interaktif dan pembagian angket sebagai timbal balik bagi tim pengabdi. Kegiatan ini dilakukan oleh pengabdi sebagai upaya pengabdi mewujudkan pendidikan karakter dan pengenalan kesehatan reproduksi pada remaja serta upaya pencegahan kekerasan seksual pada remaja khususnya di media sosial online.

\section{HASIL DAN PEMBAHASAN}

Kegiatan pengabdian masyarakat dilakukan di Sekolah Menengah Atas (SMA) Nurul Hikmah Jonggol, BogorJawa Barat tahun ajaran 2016/2017. Dihadiri oleh 60 peserta didik yanag terdiri dari perwakilan osis dan peserta didik dikelas XI dan XII serta pembina OSIS dan guru. Adapun kegiatan ini berupa kegiatan pengedukasian dan pelatihan yang berkaitan dengan kesehatan reproduksi remaja dan upaya pencegahan kekerasan seksual pada remaja khususnya pada media sosial online. Pengedukasian kesehatan seksual remaja yang berkaitan dengan menjaga kesehatan reproduksi, pola prilaku hidup sehat dan jenis penyakit seksual menular. Kegiatan ini selain pengedukasian juga pemberian pelatihan bagaimana menangani kekerasan, kejahatan dan pelecehan seksual yang dilakukan oleh korban kepada pelaku. Penanganan ini diambil dari dua sisi yakni sebelum menjadi korban dan telah menjadi korban serta penanaman karakter bertanggung jawab dalam segi agama supaya peserta didik selain memiliki kemampuan penanganan berupa pengetahuan juga penanaman karakter dari segi psikologis yakni agama.
Sebagai umpan balik kegiatan pengabdian maka pengabdi memberikan angket dengan memberikan beberapa pertanyaan. Indikator dalam pertanyaan angket adalah sebagai berikut: a. situs sosial secara online yang sering digunakan, b. tindakan saat melihat foto atau video berkonten pornografi, c. alasan menyukai seseorang (suka atau sayang) dengan lawan jenis.

Adapun hasil dari kegiatan ini adalah:

a. Situs sosial secara online yang sering digunakan: Seluruh peserta didik sering menggunakan media sosial secara online yaitu Face Book, Twiter, Whatshap dan Instagram.

b. Tindakan saat melihat foto atau video berkonten pornografi, seperti foto bermesraan dengan lawan jenis (bukan suami-istri), ada foto atau video lawan jenis dengan pakaian secara tidak tepat serta sesuatu berkaitan dengan seks. Dari hasil pengambilan data: a. melihat lalu mematikan situsnya, b. langsung menutup dan c. memblokir situs atau web yang menampilkan foto atau video berkonten pornografi.

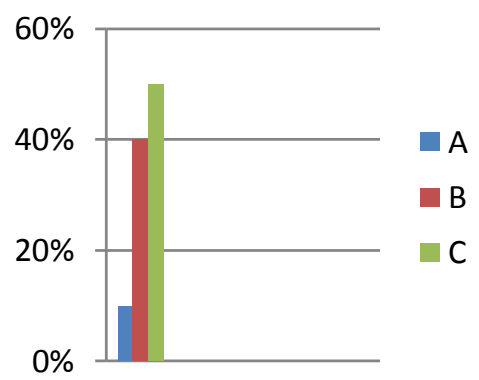

Gambar 1: Histogram tindakan saat melihat foto stau video berkonten pornografi

c. Alasan menyukai seseorang (suka atau sayang) dengan lawan jenis. a. menyukai lawan jenis karena ngefans dengan idolanya, b. sayang dan suka lawan jenis karena merasa nyaman dan senang, c. sayang dan suka lawan jenis karena hubungan kekerabatan atau menyamai dengan seorang sosok yang dituakan seperti kakak, d. sayang dan 
suka lawan jenis karena keinginan bersahabat atau berteman, e. sayang dan suka lawan jenis ingin mencari seseorang yang menjalani hubungan keseriusan akan menjadi pasangan hidup.

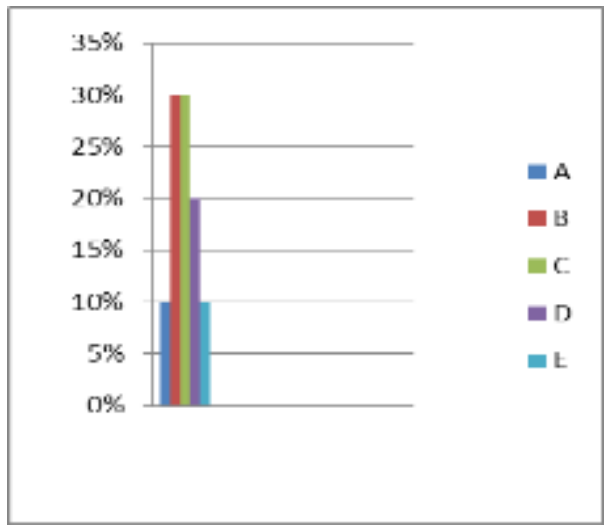

Gambar 2. Histogram alasan menyukai seseorang (suka atau sayang) dengan lawan jenis.

Dari hasil kegiatan pengabdian masyarakat yang telah dilakukan para peserta pengabdi memperoleh pengetahuan baru mengenai kesehatan reproduksi dan upaya pencegahan kekerasan seksual di media sosial secara online dan bagi pengabdi memperoleh pengetahuan dan pengalaman baru bagaimana cara melakukan pendekatan pendidikan karakter pada usai remaja pada zaman globalisasi.

\section{PENUTUP}

\section{Simpulan}

Dari hasil pengabdian yang telah dilakukan oleh pengabdi dapat disimpulkan sebagai berikut: 1) Pendidikan karakter pada lingkungan sekolah perlu dilakukan terutama dalam penanaman dasar karakter yakni sikap untuk bertanggung jawab pada diri sendiri sangatlah diperlukan. 2) Merubah paradigma pendidikan seksual dimasyarakat berupa ketabuan menjadi pendidikan seksual yang membangun karakter tanggung jawab pada remaja. 3) Kegiatan penanaman karakter berupa membangun pendidikan karakter dengan kegiatan sejenis perlu dilakukan untuk menciptakan remaja generasi globalisasi bertanggung jawab dan taat beragama.

\section{Saran}

Adapun saran yang diberikan dari kami tim pengabdi adalah: 1) Sekolah dapat terus meningkatkan dan menambahkan program pendidikan berkarakter agar para peserta didik dapat tertanam karakter terutama karakter bertanggung jawab. 2) Para orang tua peserta didik diharapkan dapat mela-kukan pengawasan terhadap anak-anak mereka terutama penggunaan media sosial secara online.

\section{Ucapan Terima Kasih}

Ucapan terimakasih kami sampaikan kepada:

1. Kepala Sekolah Menengah Atas (SMA) Nurul Hikmah Jonggol, Bogor Jawa Barat. Bapak Iik Abdul Kholiq, S.S, M.Pd.

2. Kepala Pengabdian Masyarakat Universitas Indraprasta PGRI. Bapak Munzir, M.Pd.

3. Ketua Program Studi Pendidikan Matematika. Bapak Tatan Zainal Mutakin, M.Pd.

4. Dewan Guru dan Peserta Didik sekolah menengah atas (SMA) Nurul Hikmah Jonggol, Bogor Jawa Barat.

\section{F. DAFTAR PUSTAKA}

Citra, Y. 2012. Pelaksanaan Pendidikan Karakter Dalam Pembelajaran. EJUPEKhu (Jurnal Ilmiah Pendidikan Khusus). Volume 1 Nomor 1 Januari 2012.

Fauziyah, R.N. 2016. Pengaruh Moral Judgment dan Kecerdasan Emosi terhadap Perilaku Siswa Sekolah Menengah Kejuruan Pengakses Pornografi Di Internet. Jurnal Ilmiah Penelitian Psikologi: Kajian Empiris 
\& Non-Empiris Vol. 2., No. 1., 2016. Hal. 17-27.

Kusmiati. 2016. Berbagai perilaku kenakalan remaja yang mengkhawatirkan, 10 Sep 2013. http://www. Liputan 6.com. 18 Sep 2016.

Maimunah, S. 2015. Pengaruh Faktor Keluarga terhadap Perilaku Seksual Remaja. Seminar Psikologi \& Kemanusiaan. $2015 \quad$ Psychology Forum UMM, ISBN: 978-979-796324-8. Hal. 359-362.

Mariani, A. dan Bachtiar, I. 2010. Keterpaparan Materi Pornografi dan Perilaku Seksual Siswa Sekolah Menengah Pertama Negeri. Makara, Sosial Humaniora, Vol. 14, No. 2, Desember 2010. Hal : 83-90.

Octaviani, M. 2016. Hubungan Penggunaan Jenis Media Massa Dengan Kejadian Dating Violence pada Remaja SMA Negeri 1 Pajangan,
Bantul Yogyakarta. Skripsi. Universitas 'Aisyiyah Yogyakarta. (nonpublikasi).

Triwijati, E. dan Amira, S. 2011. Tindak Kekerasan Seksual Terhadap Penyalahgunaan Kekuasaan Atau Otoritas. Pustaka Makalah Ilmu Budaya Dasar, 08 Januari 2011: http://www.smallcrab.com.

Vidya, N.T. dan Iwan, W.W. 2014. Hubungan Antara Sikap Terhadap Religiusitas dengan Sikap Terhadap Kecenderungan Perilaku Seks Pranikah pada Remaja Akhir yang Sedang Berpacaran Di Universitas Airlangga Surabaya. Jurnal Psikologi Kepribadian dan Sosial Vol. 3 No. 2 Agustus 2014. Hal. 60-69.

Viska, D. dkk 2002. Hubungan Antara Kecendrungan Perilaku Mengakses Situs Porno dan Religulitas pada Remaja. Jurnal Psikologi. 2002, NO. 1, 1-13, Hal. 1-13. 